\title{
Kombu çayı üretiminde inkübasyon sıcaklığının etkisi
}

\author{
The effect of incubation temperature on Kombu tea production
}

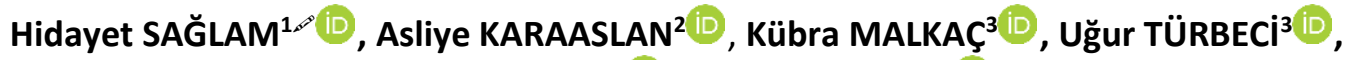
Mehmet DEMiR ${ }^{3}$, Mert Can YILDIZ ${ }^{3}$ id

${ }^{1}$ Kilis 7 Aralık University, Faculty of Art and Science, Department of Molecular Biyology and Genetics, Kilis, Turkey.

${ }^{2}$ Harran University, Sanlıurfa Technical Sciences Vocational School, Department of Food Processing, Sanlıurfa, Turkey.

${ }^{3}$ Kilis 7 Aralık University, Faculty of Engineering and Architecture, Department of Food Engineering, Kilis, Turkey.
\end{abstract}

MAKALE BILGISI / ARTICLE INFO

Makale tarihçesi / Article history:

DOI: $10.37908 /$ mkutbd.757643

Geliş tarihi /Received:25.06.2020

Kabul tarihi/Accepted:22.10.2020

\section{Keywords:}

Kombu tea, fermentation, incubation temperature, phenolic compound, antioxidant value.

\footnotetext{
Corresponding author: Hidayet SAĞLAM

$\bowtie$ : hsaglam78@gmail.com
}

\section{ÖZET / A B STRACT}

Aims: Kombu tea is a slightly sweet and acidic beverage that is consumed worldwide but has a low level of awareness in our country, resulting from the symbiotic relationship between acetic acid fermentation and alcohol fermentation. Temperature is an important parameter in the production conditions of this drink, which has many health benefits. This study aimed to determine the effect of incubation temperature and fermentation time on physicochemical and microbiological properties of kombucha tea.

Methods and Results: In this study, physicochemical and microbiological changes on days $0,5,10$ and $15^{\text {th }}$ occurring as a result of incubation in room conditions $\left(15-20^{\circ} \mathrm{C}\right)$ and incubator conditions $\left(28^{\circ} \mathrm{C}\right)$ were investigated. The $\mathrm{pH}$ of the Kombu tea samples produced at room temperature is 3.51-5.39; brix values 8.71-9.57; alcohol content 1.10$3.07 \%$; total amount of phenolic substance $374-364 \mathrm{mg}$ gallic acid $\mathrm{L}^{-1}$; antioxidant activity was determined as $80.57-76.58 \%$ and density value was $1.037-1.036 \mathrm{~g} \mathrm{~mL}^{-1}$. The $\mathrm{pH}$ of the Kombu tea samples fermented at $28^{\circ} \mathrm{C}$ is 3.22-5.39; brix 8.71-10.10; alcohol content $1.10-3.76 \%$; the total amount of phenolic substance $374-430 \mathrm{mg}$ gallic acid $\mathrm{L}^{-1}$; antioxidant activity was determined to be $80,57-80,00 \%$ and density was $1.037-1.035$ $\mathrm{g} \mathrm{mL}^{-1}$. A statistically significant difference $(p<0.05)$ in the $a^{*}$ and $b^{*}$ values on the $5^{\text {th }}$ and $10^{\text {th }}$ days of different fermentation conditions and the $L^{*}$ and $a^{*}$ values on the $15^{\text {th }}$ day has been determined. An increase in the number of microorganisms $(p<0.05)$ was detected depending on the fermentation days at both of the Kombu tea produced at different temperatures. According to the fermentation conditions at different temperatures, the increase in the number of yeast-mold was statistically insignificant, while the increase in the $5^{\text {th }}$ and $10^{\text {th }}$ days was statistically significant $(p<0.05)$ in terms of the number of bacteria.

Conclusions: Instead of standardizing the fermentation temperature and/or duration, the $\mathrm{pH}$ value of the product is considered to be an important criterion in determining the fermentation conditions in the production of Kombu tea.

Significance and Impact of the Study: In the light of these findings, if standardization is necessary, fermentation time at $28^{\circ} \mathrm{C}$ is recommended to be 10 days, or at room temperature 15 days. 


\section{GíRiş}

Kombu çayı, hafif tatlı ve hafif asidik ferahlatıcı lezzetiyle dünyada sevilerek tüketilen fermente bir üründür. Şekerli çayın fermentasyonu sonucunda mayaların ve asetik asit bakterilerinin simbiyotik ilişkisiyle oluşan fungus, ülkemizde mantar veya çay mantarı olarak adlandırımaktadır. Kombu çayı yüzeydeki selülozik ince zar ve ekşi sıvı olmak üzere iki tabakadan oluşmaktadır (Chu ve Chen, 2006; Jayabalan ve ark., 2014; Chakravorty ve ark., 2016; Güldane ve ark., 2017). Selülozik zarın üretiminden asetik asit bakterileri sorumludur. Bakteriyel selüloz olarak adlandırılan bu zarı üreten ve üzerinde bilimsel çalışmalar yapılan Gluconacetobacter xylinus kombu çayından izole edilebilmektedir (Nguyen ve ark., 2008; Karahan ve ark., 2011).

Kombu çayının fermentasyonunda asetik asit bakterilerinin yanı sıra farklı cinsten mayalar da görev yapmaktadır. Kombu çayı mantarının mikroorganizma çeşitliliği dünya çapında farklılık göstermekle birlikte asetik asit bakterilerinden Acetobacter, Bacterium ve Gluconobacter cinslerine ait türler mevcuttur. Mayalar ise Schizosaccharomyces, Saccharomycodes, Saccharomyces, Candida, Kloeckera, Zygosaccharomyces, Brettanomyces, Kluyveromyces, Torulaspora ve Torula cinslerinin türlerinden oluşmaktadır. Ancak bazı çalışmalarda Lactobacillus cinsine ait türlerin varlığı da belirlenmiştir (Sievers ve ark., 1995; Kurtzman ve ark., 2001; Şafak ve ark., 2002; Chakravorty ve ark., 2016).

Kombu çayının hazırlanmasında kombu mantarı (çay mantarı) şekerli (sakkaroz) çaya aşılanarak fermentasyona bırakılmaktadır (Loncar ve ark., 2006; Jayabalan ve ark., 2014). Ancak kombu çayı farklı hammaddelerle de üretilebilmektedir. Hammaddelerin farklılaşması son ürün kalitesini de etkilemektedir. Şeker olarak sakkaroz yerine laktoz, glikoz veya fruktozun kullanıldığı çalışmalarda etanol ile laktik asit bileşiminde farklılıklar belirlenmiştir (Reiss, 1994). Diğer çalışmalarda ise melas (Malbasa ve ark., 2008a; Malbasa ve ark., 2008b), nane çayı, ıhlamur çayı, bira, kola (Reiss, 1994), limon balsam çayı, yeşil çay ve beyaz çay (Güldane ve ark., 2017) hammadde olarak kullanılmıştır. Hammaddenin farklılaşması organik asit çeşidi açısından da belirleyici olmaktadır. Örneğin yeşil çayda fermentasyonla asetik asit, siyah çayda ise glukuronik asit üretildiği saptanmıştır (Jayabalan ve ark., 2007). Ayrıca kombu mantarı yoğurt ve kefir yapımında (Malbasa ve ark., 2009) ve peynir altı suyu fermentasyonunda (Belloso-Morales ve HernandezSanchez, 2003) kullanılmıştır.
Kombu çayı fermentasyonu ile oluşan temel metabolitler asetik, glukonik, glukuronik, L-laktik, malonik, piruvik ve usnik asitler ile etanol, gliserol, glukonolaktondur (Teoh ve ark., 2004; Blanc, 1996; ileriBüyükoğlu ve ark., 2010; Jayabalan ve ark., 2015). Kombu çayı kompozisyonunda mayalar sakkarozu glikoz ve fruktoza parçalamakta ve etanol üretmektedirler. Asetik asit bakterileri ise fruktozdan asetik asit ve glikozdan glukonik asit meydana getirmektedirler. Bakteriler esas olarak asetik asit, glukonik asit ve selüloz üretmektedirler (Reiss, 1994; Sievers ve ark., 1995; Liu ve ark., 1996; Jayabalan ve ark., 2007). Ancak Sreeramulu ve ark. (2001)'nın yaptıkları çalışmada elde edilen ürünlerde laktik asit ve etanol varlığına rastlanmamıştır.

Kombu çayı fermentasyonu sırasında mikroorganizma sayıları artmakta, ancak asitlikteki gelişmeye bağlı olarak sayıda azalma meydana gelmektedir. Mikroorganizma sayılarındaki artış kombu çayı mantarına, üretim koşullarına ve kullanılan hammaddelere göre farklıık göstermektedir. Örneğin Jayabalan ve ark. (2007)'nin yaptığı çalışmada toplam bakteri ve maya sayılarının 9 günlük fermentasyon sürecinde hızlı bir şekilde arttığı ve 9. günden sonra ise azalma gösterdiği belirlenmiştir. Tayvan'da yapılan bir çalışmada ise farklı orijinli dokuz çay mantarı ile yapılan fermentasyonda maya sayısının fermentasyon başlangıcında artmaya başladığı ve maksimum seviyelere 6-14. günlerde ulaştığı belirtilmektedir (Chen ve Liu, 2000).

Kombu çayı özellikleri açısından kullanılan hammadde, mikroorganizma çeşitliliği ve sayısının yanı sıra üretim koşulları da önem taşımaktadır. Özellikle inkübasyon süresi ve sıcaklığı kaliteyi belirleyen önemli parametrelerdendir. Kombu çayı dünyada genellikle evde üretildiğinden sıcaklık ve $\mathrm{pH}$ kontrolü yapılamamakta ve asitliği daha yüksek ürünler elde edilmektedir (Malczewski, 2001). Yapılan kaynak taramasında üretim koşullarının kombu çayı kalitesine etkisi üzerine yapılmış sınırlı sayıda çalışmaya rastlanmıştır.

Yapılan bu çalışmada inkübasyon sıcaklığı (oda sıcaklığı ve $28^{\circ} \mathrm{C}$ ) ve fermentasyon süresinin kombu çayının $\mathrm{pH}$, briks, etanol miktarı, toplam fenolik madde, toplam antioksidan aktivite, yoğunluk ve renk gibi fizikokimyasal ile maya-küf ve toplam canlı sayısı gibi mikrobiyolojik özelliklerine etkisi incelenmiştir. 


\section{MATERYAL ve YÖNTEM}

\section{Materyal}

Kombu çayı; çay (Lipton Filiz Çay), sakaroz (Bal Küpü Şeker) ve içme suyu (İdeal Su, Osmaniye) kullanılarak üretilmiştir. Bu hammaddeler (Kilis) ve ticari mantar yerel bir marketten temin edilmiştir (Anonymous, 2020).

\section{Metot}

Kombu çayı üretiminde içme suyu kaynamaya başladıktan sonra içine $\% 10(\mathrm{w} / \mathrm{v})$ oranında toz şeker katılmış ve beş dakika daha kaynatılmıştır. Şekerli suyun kaynama işlemi tamamlandıktan sonra buna \%1 (w/v) oranında siyah çay katılmıştır. Çay 15 dakika kadar demlenmeye bırakılmış, daha sonra süzülmüştür. Süzüntü iki kısma ayrılarak biri oda sıcaklığı, diğeri $28^{\circ} \mathrm{C}^{\prime}$ ye kadar soğutulmuştur. Her iki çay ekstraktı geniş ağızlı steril cam kavanozlara boşaltılmıştır. Kombu çayı üretiminde kullanılan mantar aşılandıktan sonra kavanozların ağzı havalanmayı sağlamak üzere steril tülbentlerle örtülmüştür (Reiss, 1994; Jayabalan ve ark., 2014). Bu şekilde ön hazırlıkları tamamlanan örneklerden analizler için yeterli miktarlarda ayrıldıktan sonra inkübasyona bırakılmıştır. Çalışma 3 tekerrürlü olarak gerçekleştirilmiştir.

\section{Fizikokimyasal Analizler}

Farklı sıcaklık ortamlarında üretimi gerçekleştirilen kombu çaylarının $\mathrm{pH}$, briks, alkol, renk, toplam fenolik madde, toplam antioksidan aktivite ve yoğunluk tayinleri gerçekleştirilmiştir (Singh ve ark., 2002; Uçan Türkmen ve ark., 2019a). Toplam fenolik madde miktarları ile antioksidan aktivite tayinleri 0 . ve 15 . günlerde incelenmiş, diğer parametrelerin 0., 5., 10. ve 15. günlerdeki değerlerine bakılmıştır.

$\mathrm{pH}$ : $\mathrm{pH}$ değerleri cam elektrotlu ISOLAB marka $\mathrm{pH}$ metre kullanılarak ölçülmüştür.

Briks: Briks değerleri masa tipi el refraktometresi (Milwaukee MA871 Refractometer) ile $+20^{\circ} \mathrm{C}^{\prime}$ de belirlenmiştir.

Renk: Renk (CIE L*, a*, b*) analizi, el tipi renk cihazı (HunterLab miniscan EZ, ABD) ile belirlenmiştir.

Alkol: Alkolmetre (Vino-O-Metre) ile numunelerde alkol ölçümü yapılmıştır.

Toplam fenolik madde: Kombu çayının çözünebilen toplam fenolik madde içeriği Folin-Ciocalteu ayıracı yardımıyla incelenmiştir. Çayların $0.5 \mathrm{~mL}$ 'sine $2,5 \mathrm{~mL}$ Folin-Ciocalteu reaktifi (\%10) ve $2.5 \mathrm{~mL} \mathrm{NaHCO}$ (\%7.5) çözeltisi eklenmiş ve $45^{\circ} \mathrm{C}^{\prime}$ de 45 dakika süresince su banyosunda bekletilmiştir. Absorbanslar 765 nm'de spektrofotometrik olarak ölçülmüş ve gallik asidin kullanıldığı standart kalibrasyon grafiğine göre, toplam fenolik içerik gallik asit eşdeğerleri (mg GAE L-1) olarak ifade edilmiştir. Uçan Türkmen ve ark. (2019b)'nın kullandığı yöntem revize edilerek çalışmada kullanılmıştır.

Antioksidan aktivite: Kombu çayının antioksidan aktivitesi DPPH (2,2-diphenyl 1-picrylhydrazyl) radikali kullanılarak Uçan Türkmen ve ark. (2019b)'nın kullandığı metoda göre analiz edilmiştir. Çayların $100 \mu \mathrm{L}$ 'sine, 3.9 $\mathrm{mL}$ metanol içerisinde hazırlanmış DPPH radikali $(0,025$ $\mathrm{g} \mathrm{L}^{-1}$ ) ilave edilmiştir. Karışım 2 saat boyunca karanlıkta ve oda sıcaklığında bekletilmiştir. Bu analiz DPPH çözeltisinin mor renginin açılması esasına dayandığından reaksiyona girmeyen DPPH 515 nm'de spektrofotometrede belirlenmiştir. DPPH inhibisyonu aşağıdaki formüle göre \% olarak hesaplanmıştır.

$\%$ Antioksidan $=\left(\frac{A_{\text {kontrol }}-A_{\text {örnek }}}{A_{\text {kontrol }}}\right) \times 100$

Eq. 1

\section{Mikrobiyolojik Analizler}

İki farklı sıcaklıkta (oda sıcaklığı ve $28^{\circ} \mathrm{C}$ ) üretilen kombu çayı örneklerinden fermentasyonun başlangıcında, 5 . 10. ve 15. günlerinde alınan örneklerde maya-küf ve toplam mezofilik aerobik bakteri sayımı yapılmıştır. Gerekli seyreltmeler yapıldıktan sonra maya-küf sayımı için Potato Dextrose Agar (PDA)'a ekim yapılmış ve Petri kutuları $25^{\circ} \mathrm{C}^{\prime}$ de 5 gün süresince inkübe edilmiştir. Toplam mezofilik aerobik bakteri sayımı için ise Nutrient agara uygun seyreltilerden ekim yapılmış ve Petri kutuları $28^{\circ} \mathrm{C}^{\prime}$ de 48 saat inkübasyona bırakılmıştır (Erkmen, 1996; Çakmakçı ve ark., 2017). İnkübasyon süresi tamamlandıktan sonra Petri kutularında sayım yapılarak elde edilen sonuçlar Koloni Oluşturan Birim $(\mathrm{KOB}) / \mathrm{mL}$ şeklinde belirtilmiştir.

\section{istatistiksel Analiz}

Elde edilen veriler SPSS 16.0 istatistik paket programı kullanılarak varyans analizine tabi tutulmuş ve gruplar arasında önemli bulunan farklılıklar t-test kullanılarak belirlenmiştir.

\section{BULGULAR ve TARTIŞMA}

\section{Fizikokimyasal Analiz Sonuçları}

Kombu çayı ile ilgili görseller Şekil 1'de verilmiştir. Illk karedeki rengin açılması, oluşan asitlikten kaynaklanmaktadır. İkinci karedeki ise birden fazla 15 günlük fermentasyona tabi tutulan kombu çayının selülozik yapısı görülmektedir. 
Kombu çayının $\mathrm{pH}$, alkol (\%), yoğunluk $\left(\mathrm{g} \mathrm{mL}^{-1}\right)$, antioksidan aktivite (\%) ve toplam fenolik madde (mg GAE $L^{-1}$ ) sonuçları Çizelge $1^{\prime}$ de verilmiştir.

$p H$ : Kombu çayı üretiminde fermentasyon işleminin yeterliliğinin belirlenmesinde $\mathrm{pH}$ değeri dikkate alınmaktadır (Reiss, 1994; Chen ve Liu, 2000; Dufresne ve Farnworth, 2000; Sreeramulu ve ark., 2000; Jayabalan ve ark., 2008; Malbasa ve ark., 2011; Velicanski ve ark., 2014; Sun ve ark., 2015). Bu çalışma sonunda, farklı sıcaklıktaki fermentasyon süresinin $\mathrm{pH}$ üzerindeki etkisinin önemli $(p<0.05)$ olduğu tespit edilmiştir. Günlere bağlı olarak (5., 10. ve 15. günler) farklı fermentasyon sıcaklıklarında örnekler arasındaki farklıığın önemli $(p<0.05)$ olduğu belirlenmiştir. Üç tekerrür şeklinde düzenlenen çalışmada, fermentasyona tabi tutulan çayın ilk hazırlandığında (0. gün) $\mathrm{pH}$ değerlerinin ortalaması 5,39 olarak tespit edilmiştir. 28 ${ }^{\circ} C^{\prime}$ lik fermentasyon sıcaklığında 15 günün sonunda en düşük $\mathrm{pH}$ değerinin 3,22 olduğu belirlenmiştir.

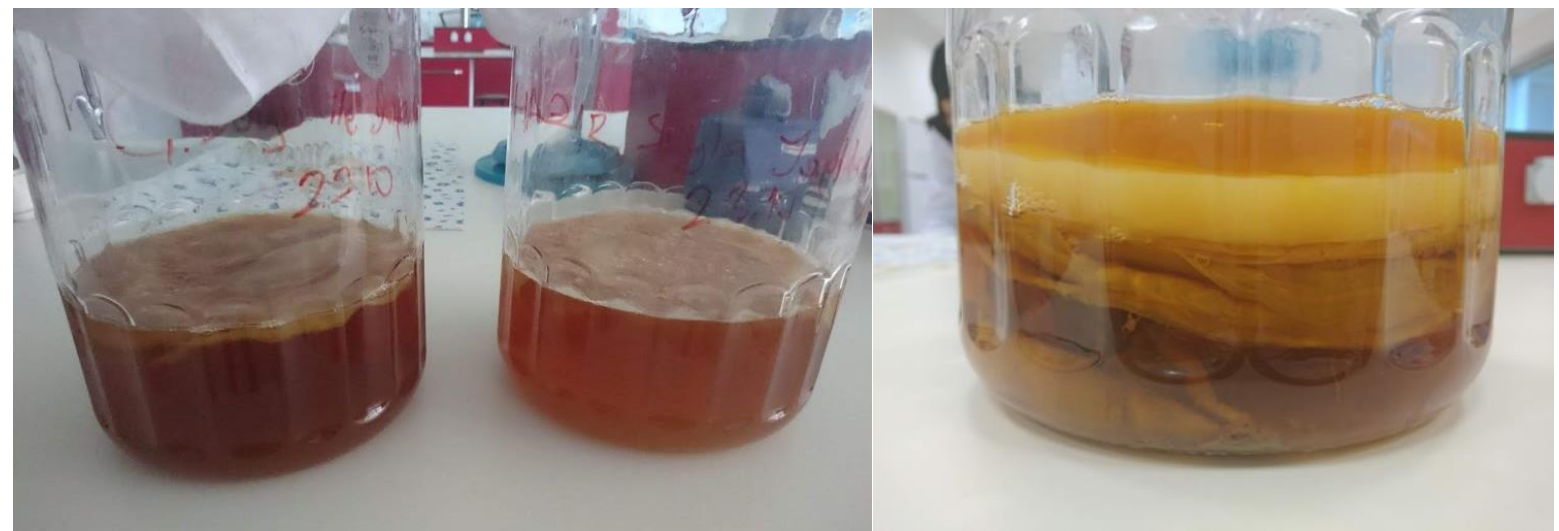

Şekil 1. Kombu çayı ile ilgili bazı görseller

Figure 1. Some visuals of kombucha

Çizelge 1. Kombu çayının bazı özellikleri

Table 1. Some properties of kombucha tea

\begin{tabular}{|c|c|c|c|c|c|}
\hline $\begin{array}{c}\text { Analiz } \\
\text { Analysis }\end{array}$ & Sicaklık & 0. gün & 5. gün & 10. gün & 15. gün \\
\hline \multirow[t]{2}{*}{$\mathrm{pH}$} & $28^{\circ} \mathrm{C}$ & $5.39^{\mathrm{a}, \mathrm{A}} \pm 0.19$ & $3.58^{\mathrm{ab}, \mathrm{A}} \pm 0.02$ & $3.47^{\mathrm{ab}, \mathrm{A}} \pm 0.00$ & $3.22^{\mathrm{b}, \mathrm{A}} \pm 0.07$ \\
\hline & Oda & $5.39^{\mathrm{a}, \mathrm{A}} \pm 0.19$ & $3.70^{b, B} \pm 0.04$ & $3.69^{b, B} \pm 0.01$ & $3.51^{b, B} \pm 0.12$ \\
\hline \multirow[t]{2}{*}{ Briks } & $28^{\circ} \mathrm{C}$ & $8.71^{\mathrm{a}, \mathrm{A}} \pm 1.16$ & $10.10^{\mathrm{a}, \mathrm{A}} \pm 0.51$ & $9.45^{a, A} \pm 0.41$ & $8.67^{a, A} \pm 0.32$ \\
\hline & Oda & $8.71^{\mathrm{a}, \mathrm{A}} \pm 1.16$ & $9.57^{\mathrm{a}, \mathrm{A}} \pm 0.64$ & $9.35^{\mathrm{a}, \mathrm{A}} \pm 0.15$ & $9.10^{\mathrm{a}, \mathrm{A}} \pm 0.07$ \\
\hline \multirow[t]{2}{*}{ Alkol Tayini (\%) } & $28^{\circ} \mathrm{C}$ & $1.10^{\mathrm{a}, \mathrm{A}} \pm 0.03$ & $3.76^{\mathrm{b}, \mathrm{A}} \pm 0.15$ & $3.30^{\mathrm{b}, \mathrm{A}} \pm 0.43$ & $2.17^{\mathrm{c}, \mathrm{A}} \pm 0.06$ \\
\hline & Oda & $1.10^{\mathrm{a}, \mathrm{A}} \pm 0.03$ & $3.07^{b c, B} \pm 0.12$ & $2.67^{b c, A} \pm 0.49$ & $2.10^{c, A} \pm 0.10$ \\
\hline \multirow[t]{2}{*}{ Yoğunluk (g mL ${ }^{-1}$ ) } & $28^{\circ} \mathrm{C}$ & $1.037^{\mathrm{a}, \mathrm{A}} \pm 0.000$ & $1.037^{\mathrm{ab}, \mathrm{A}} \pm 0.000$ & $1.035^{\mathrm{ab}, \mathrm{A}} \pm 0.001$ & $1.035^{\mathrm{bc}, \mathrm{A}} \pm 0.001$ \\
\hline & Oda & $1.037^{\mathrm{a}, \mathrm{A}} \pm 0.000$ & $1.037^{\mathrm{a}, \mathrm{A}} \pm 0.002$ & $1.036^{\mathrm{a}, \mathrm{A}} \pm 0.001$ & $1.036^{\mathrm{a}, \mathrm{A}} \pm 0.000$ \\
\hline Toplam fenolik madde & $28^{\circ} \mathrm{C}$ & $374^{A} \pm 51$ & - & - & $430^{A} \pm 11$ \\
\hline (mg GAE L-1) & Oda & $374^{\mathrm{A}} \pm 51$ & - & - & $364^{A} \pm 45$ \\
\hline Antioksidan aktivite & $28^{\circ} \mathrm{C}$ & $80.57^{A} \pm 6.23$ & - & - & $80^{A} \pm 0.00$ \\
\hline (\%) & Oda & $80.57^{A} \pm 6.23$ & - & - & $76.58^{\mathrm{B}} \pm 0.95$ \\
\hline
\end{tabular}

*Satırlarda farklı küçük harfler ile gösterilen fermentasyon süresi arasındaki farklılıklar 0.05 düzeyinde önemlidir.

Sütunlarda farklı büyük harfler ile gösterilen fermentasyon koşulları arasındaki farklılıklar 0.05 düzeyinde önemlidir.

Fermentasyon işlemi sırasında, bakteri ve mayalar sakkarozu asetik asit ve glukuronik asit gibi birtakım organik asitlere metabolize etmektedirler (Sievers ve ark., 1995). Bu organik asitlerin artan konsantrasyonu nedeniyle, $\mathrm{pH}$ değeri azalmaktadır. Asetik asit bakterilerinin optimum çoğalma sıcaklıklarının $28^{\circ} \mathrm{C}$ (Karahan ve ark., 2011), mayaların $25-28^{\circ} \mathrm{C}$ aralığında (Boulton ve Quain, 2001) olması dolayısıyla fermentasyon koşullarındaki pH farkının mikroorganizmaların $28^{\circ} \mathrm{C}$ de daha fazla çoğalma göstermelerinden kaynaklandığı düşünülebilir. Değirmencioğlu ve ark. (2019) yaptıkları çalışmada farklı çay yapraklarının kullanılmasına karşılık pH değerlerinde önemli bir farklılık olmadığı ifade edilmiştir. Birçok çalışmada fermentasyon sonu $\mathrm{pH}$ değerinin 1.80-4.70 aralığında değişkenlik gösterdiği belirtilmektedir (Reiss, 1994; Sreeramulu ve ark., 2000; El-Siddig Ahmed, 2003; Loncar ve ark., 2006; Jayabalan ve ark., 2007; Jayabalan 
ve ark., 2008; Chakravorty ve ark., 2016; GramzaMichalowska ve ark., 2016; Güldane ve ark., 2017; Neffe-Skocinska ve ark., 2017; Amarasinghe ve ark., 2018; Primiani ve ark., 2018). Bu çalışmada belirlenen $\mathrm{pH}$ değerlerinin önceki çalışmalardaki $\mathrm{pH}$ değerleri ile uyumlu olduğu belirlenmiştir. Fermentasyonun 5 . günündeki $\mathrm{pH}$ değerindeki azalmanın diğer 5 günlük periyotlardaki azalmadan daha fazla olduğu tespit edilmiştir. Bu durum çay yapraklarındaki mineral maddeler ve fermentasyon ile oluşan zayıf asitlerin etkisi ile açıklanabilir. pH'daki değişim kombu üretimindeki fermentasyonun tipik bir özelliği olarak karşımıza çıkmaktadır. $\mathrm{pH}^{\prime}$ daki değişimden dolayı fermentasyonun $\quad 28^{\circ} \mathrm{C}^{\prime} \mathrm{de} \quad$ gerçekleştirilmesi fermentasyon işleminin daha kısa sürebileceğini göstermektedir.
Briks: $28^{\circ} \mathrm{C}^{\prime}$ lik fermentasyon sıcaklığında üretilen kombu çayı örneklerinin briks değerlerinin 8.71-10.10 aralığında değişim gösterdiği, buna karşın oda sıcaklığında üretilen kombu çayı örneklerinin 8.71-9.10 aralığında olduğu belirlenmiştir (Çizelge 1; Şekil 2). Fermentasyonun 5. gününde briks değerlerinde istatistiksel olarak önemsiz düzeyde bir artış gözlenmiş ve daha sonra fermentasyon süresince istatistiksel olarak önemsiz düzeyde bir azalma tespit edilmiştir ( $p$ $>0.05$ ). Bunun nedeni, kombu çayı üretiminde kullanılan sakkarozun, mayalar ve işlem sıcaklığı etkisiyle glikoz ve früktoza inversiyonundan kaynaklandığı düşünülebilir. Briks değerlerinin 5. günden sonra azalması mikroorganizmaların glikozu kullanmaları ile açıklanabilir.

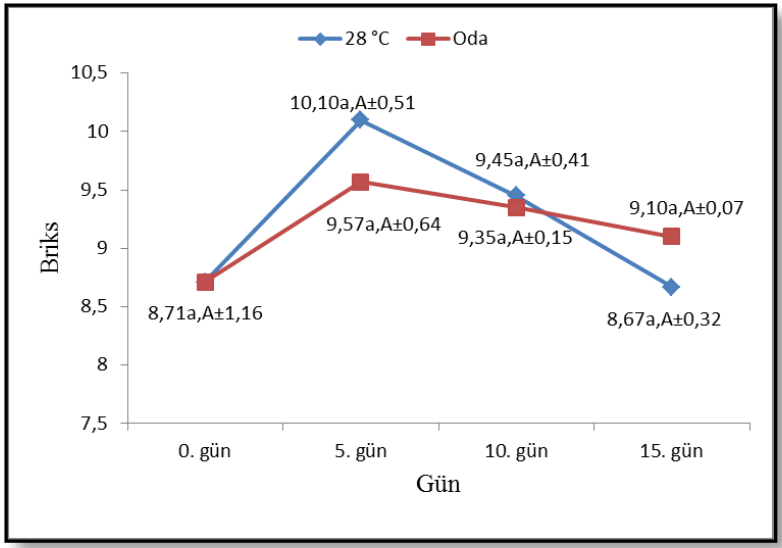

Şekil 2. Kombu çayı örneklerinin briks değerleri

Figure 2. Brix values of kombucha samples.

* Satırlarda farklı küçük harfler ile gösterilen fermentasyon süresi arasındaki farklılıklar 0.05 düzeyinde önemlidir.

Sütunlarda farklı büyük harfler ile gösterilen fermentasyon koşulları arasındaki farklılıklar 0.05 düzeyinde önemlidir.

Alkol: Aynı fermentasyon sıcaklığında alkol oranının günlere bağlı olarak önemli düzeyde $(p<0.05)$ değiştiği tespit edilmiştir. Aynı şekilde farklı fermentasyon sıcaklığında sadece 5.günde alkol oranı önemli düzeyde ( $p<0.05$ ) değişmiştir. Oda ve $28^{\circ} \mathrm{C}^{\prime}$ lik fermentasyon sıcaklığında en yüksek etanol değerlerinin 5 . gün sonunda ortaya çıktığı belirlenmiştir. Elde edilen sonuçlar, Wang ve ark. (2014)'nin yaptıkları çalışma ile paralellik göstermektedir. Chakravorty ve ark. (2016) tarafından yapılan çalışmada etanol değerlerinin maksimum seviyesi 7. günde tespit edilmiştir. Güldane ve ark. (2017) tarafından farklı hammaddeler kullanılarak kombu çayı üretimi yapılan çalışmada hammaddeye bağlı olarak alkol oranları arasındaki istatistiksel olarak fark belirlenmiştir. El-Siddig Ahmed'in (2003) yaptığı çalışmada kombu çayında alkol belirlenememiştir. Ayrıca, kombu çayının üretiminde havalandırma işleminin azaltılması ile \%2.5 oranında alkol elde edilebileceği belirtilmektedir. Yapılan çalışmada alkol oranları diğer çalışmalarla farklılık gösterse de yapılan birçok çalışmada kombu çaylarının farkı alkol konsantrasyonlarının temel nedeninin mikrobiyal koloni ve/veya fermentasyonda uygulanan sürenin farklı olmasından kaynaklandığı belirtilmektedir (Kallel ve ark., 2012; Chakravorty ve ark., 2016).

Yoğunluk: Yoğunluk tayinine göre kombu çayı üretiminde oda sıcaklığında günlere bağlı olarak önemli düzeyde farklılık görülmemiştir. Buna karşılık, $28^{\circ} \mathrm{C}^{\prime} l i k$ fermentasyon sıcaklığında günlere bağlı olarak yoğunlukta önemli düzeyde ( $p<0.05$ ) azalma tespit edilmiştir. Yapılan bir çalışmada, 8 günlük fermentasyon sonunda kombu çayının yoğunluğu $1.019 \mathrm{~g} \mathrm{~mL}^{-1}$ den $1.013 \mathrm{~g} / \mathrm{mL}^{-1}$ ye kadar azaldığı belirlenmiştir. Meydana gelen yoğunluk azalması şekerin tüketilmesi ile açıklanmıştır (Coton, ve ark., 2017). Elde edilen yoğunluk değerlerinin, yapılan çalışma ile farklı olması, 
eklenen şeker miktarının farklılığından meydana geldiği düşünülmektedir.

Toplam Fenolik Madde: Üretimi gerçekleştirilen kombu çayının toplam fenolik madde miktarlarının oda sıcaklığında 374-364 mg GAE $\mathrm{L}^{-1}$ aralığında, $28^{\circ} \mathrm{C}^{\prime}$ lik fermentasyon sıcaklığında $374-430 \mathrm{mg}$ GAE L L aralığında olduğu belirlenmiştir. Buna göre $28^{\circ} \mathrm{C}^{\prime}$ lik fermentasyon sıcaklığında fenolik madde miktarında artış belirlenirken, oda sıcaklığında üretimi yapılan kombu çayının fenolik madde miktarında azalma tespit edilmiştir. Farklı fermentasyon sıcaklığındaki toplam fenolik madde miktarları arasında istatistiksel olarak önemli bir fark tespit edilememiştir. Güldane ve ark. (2017) yaptıkları çalışmada kombu çayının fenolik madde miktarının $228.35 \mathrm{mg} \mathrm{GAE} \mathrm{L}^{-1}$ olduğunu tespit etmişlerdir. Yapılan çalışmalarda kombu çayı üretimi ile toplam fenolik madde değerinin arttığı belirtilmektedir
(Chu ve Chen, 2006; Velicanski ve ark., 2014; Pure ve Pure, 2016b). Farklı koşullarda fermentasyona tabi tutulan kombu çaylarının fenol konsantrasyonlarının değişiklik göstermesi kombu mantarı tarafından üretilen enzimler tarafından fenolik bileşiklerin farklı bileşiklere dönüştürülmesi ile açıklanmaktadır. Ayrıca, kateşinler gibi fenolik bileşikler kombu çayı fermentasyonu sırasında aside duyarlı hücrelerden ortama geçebildiği bildirilmiştir. Öte yandan, kateşinler gibi fenolik bileşikler daha yüksek moleküler kütleye sahip moleküllere polimerize olabilmekte ve böylece polifenollerin miktarı azalabilmektedir (Chu ve Chen, 2006). Bu durumlar değerlendirildiğinde $28^{\circ} \mathrm{C}^{\prime}$ lik fermentasyon sıcaklığına tabi tutulan kombu çaylarının polifenolik içeriğinin artmasının nedeninin yukarıda belirtilen hususlar olabileceği düşünülmektedir.
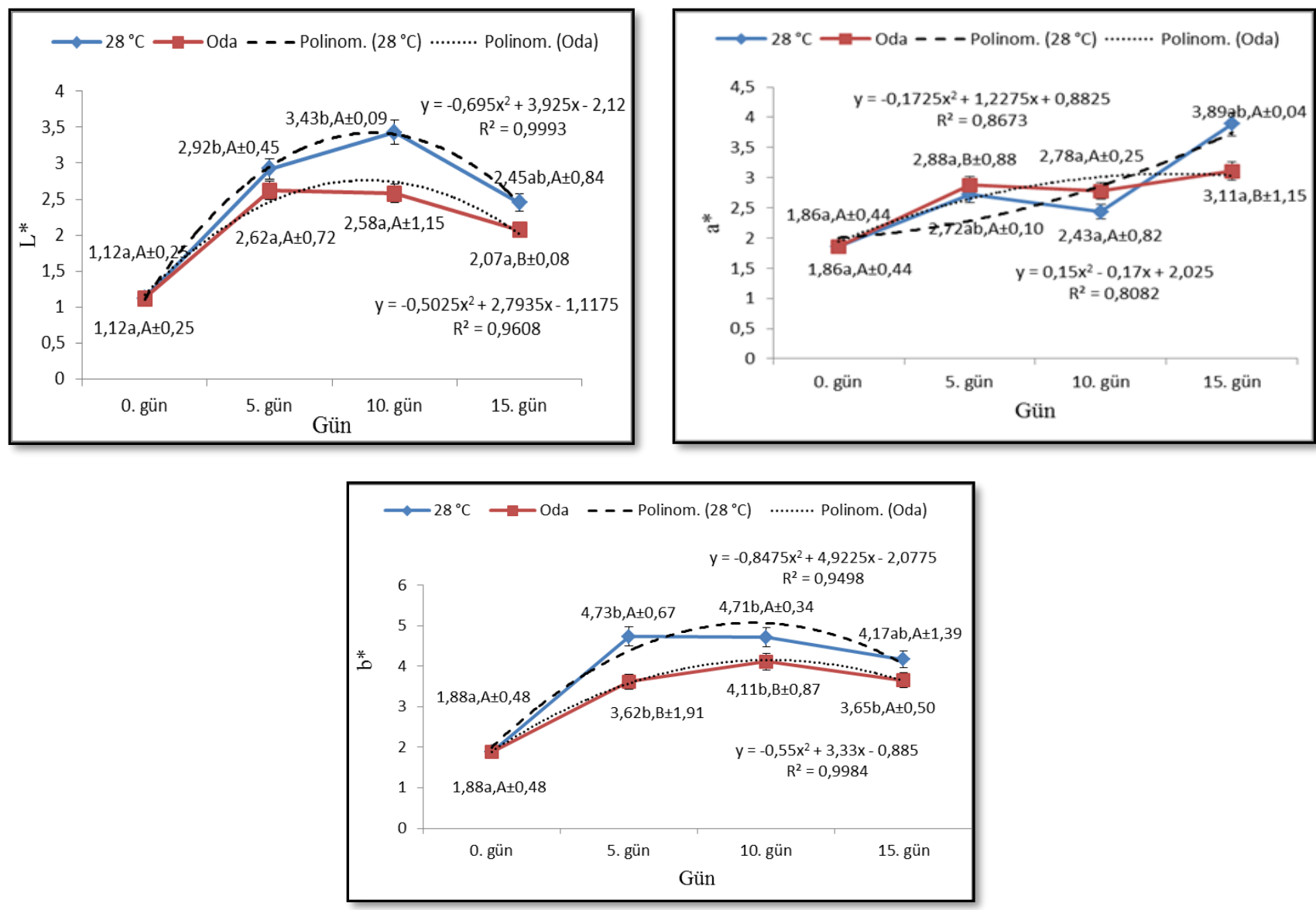

Şekil 3. Etüv ve oda koşullarında fermente edilen kombu çayının renk profili

Figure 3. Color profile of kombucha produced under oven and room conditions.

* Satırlarda farklı küçük harfler ile gösterilen fermentasyon süresi arasındaki farklılıklar 0.05 düzeyinde önemlidir.

Sütunlarda farklı büyük harfler ile gösterilen fermentasyon koşulları arasındaki farklılıklar 0.05 düzeyinde önemlidir.

Antioksidan aktivitesi: Çalışmada çayın oda sıcaklığındaki antioksidan aktivitesi \%80.57-76.58 aralığında tespit edilmiştir. $28^{\circ} \mathrm{C}^{\prime}$ lik fermentasyon sıcaklığında çayın antioksidan aktivitesi ise \%80.5780.00 aralığında belirlenmiştir. Fermentasyon işleminin 15. gününe göre farklı fermentasyon sıcaklıklarında 
antioksidan aktivitede önemli düzeyde $(p<0.05)$ farklılık söz konusudur. Velicanski ve ark. (2014) tarafından yapılan bir çalışmada kombu çayı üretiminde ilk günden sonra kombu çayının antioksidan aktivitesinin 3. güne kadar arttığı, bu artıştan sonra azalma gösterdiği daha sonra inkübasyonun 7. gününde arttığı tespit edilmiştir. Elde edilen değerlere göre $72.3 \mu \mathrm{L} \mathrm{mL}{ }^{-1}-91.2 \mu \mathrm{L} / \mathrm{mL}^{-1}$ aralığında DPPH değerine sahip olduğu belirlenmiştir. Çalışmada elde edilen değerler bu aralıkta olduğundan, analiz sonucu diğer çalışmalarla uyum göstermektedir. Buna karşılık yapılan bazı çalışmalarda kombu çayı oluşumu sonrasında çayın antioksidan aktivitesinin arttığı ifade edilmektedir (Jayabalan ve ark., 2008; Chu ve Chen, 2006).

Renk: Yapılan çalışmada $\mathrm{L}^{*}, \mathrm{a}^{*}$ ve $\mathrm{b}^{*}$ değerlerin $28^{\circ} \mathrm{C}^{\prime}$ lik fermentasyon sıcaklığında istatistiksel olarak önemli şekilde artı̧̧ gösterdiği belirlenmiştir $(p<0.05)$.

Oda sıcaklığında ise sadece $b^{*}$ değerleri önemli düzeyde ( $p<0.05)$ artı̧̧ gösterirken, diğer parametrelerin artışının istatistiksel olarak önemsiz olduğu ( $p>0.05$ ) belirlenmiştir. Ayrıca, istatistiksel olarak önemli düzeydeki sonuçların eğilim çizgileri, eğrilerin denklemleri ile $\mathrm{R}^{2}$ değerleri oluşturulmuş ve hata çubukları eklenmiştir (Şekil 3). Oda sıcaklığı ile $28^{\circ} \mathrm{C}^{\prime}$ lik fermentasyon sıcaklığı karşılaştırıldığında 15 . gündeki L* değerleri, 5. ve 15. günlerdeki a* değerleri ile 5 . ve 10. günlerdeki $b^{*}$ değerleri önemli farklılık göstermişlerdir (p <0.05). Yapılan çalışmada oda sıcaklığında fermentasyona tabi tutulan Kombu çayının $L^{*}$ değerleri,
1.12-2.62, a* değerleri 1.86-3.11 ve $b^{*}$ değerleri 1.884.11 aralığında olduğu tespit edilmiştir. $28^{\circ} \mathrm{C}^{\prime}$ lik fermentasyon sıcaklığında ise kombu çayının $L^{*}$ değerleri 1.12-3.43, a* değerleri 1.86-3.89, b* değerleri 1.88-4.73 aralığında olduğu tespit edilmiştir. L* değerlerine göre fermentasyon sonucunda kombu çayının renginin açıldığı belirlenmiştir. $a^{*}$ ve $b^{*}$ değerlerine göre artış tespit edilmiştir. Bu değişimlerin $\mathrm{pH}^{\prime}$ nın değişmesi sonucu fenolik bileşiklerdeki değişimlerden kaynaklandığı düşünülebilir. Yapılan çalışmalar incelendiğinde kombu çayının renk analizi ile ilgili veriye rastlanmamıştır.

\section{Mikrobiyolojik Analizler}

Mikrobiyal analiz sonuçları Çizelge 2'de verilmiştir. Elde edilen sonuçlara göre kombu çayının fermente edildiği sıcaklığa bağlı olarak mikroorganizma sayılarında önemli düzeyde $(p<0.05)$ artış tespit edilmiştir. Oda ve $28^{\circ} \mathrm{C}^{\prime}$ lik fermentasyon sıcaklığındaki Toplam mezofilik bakteri sayıları (TMBS) 5. ve 10. günlerde önemli düzeyde ( $p$ $<0.05)$ farklıık göstermiş̧ir. Sreeramulu ve ark. (2000)'nın yaptıkları çalışmada asetik asit üreten bakterilerin ve mayaların sayısının 4. güne kadar yükseldiği ve daha sonra azaldığı belirtilmektedir. ElSiddig Ahmed (2003) tarafından yapılan bir çalışmada bakteri sayısının 6 . güne kadar yükselme gösterdiği ve daha sonra azaldığı ifade edilmektedir. Aynı çalışmada, maya sayısının 5.güne kadar değişen oranlarda azaldığı daha sonra artış gösterdiği belirtilmektedir.

Çizelge 2. Kombu çayının mikrobiyal analiz sonuçları

Table 2. Results microbial analysis of kombucha tea.

\begin{tabular}{|c|c|c|c|c|}
\hline Mikroorganizma sayıları & 0. gün & 5.gün & 10.gün & 15.gün \\
\hline $\begin{array}{l}\left.\text { Maya-Küf Sayısı (KOB mL }{ }^{-1}\right)\left(28^{\circ} \mathrm{C}\right) 10^{5} \\
\text { Maya-Küf Sayısı }\left(\mathrm{KOB} \mathrm{mL}^{-1}\right)(\mathrm{Oda}) 10^{5}\end{array}$ & $\begin{array}{l}9.7^{\mathrm{a}, \mathrm{A}} \pm 1.15 \\
9.7^{\mathrm{a}, \mathrm{A}} \pm 1.15\end{array}$ & $\begin{array}{c}68^{\mathrm{a}, \mathrm{b}, \mathrm{A}} \pm 8 \\
115^{\mathrm{a}, \mathrm{A}} \pm 57\end{array}$ & $\begin{array}{c}73^{\mathrm{ab}, \mathrm{A}} \pm 15 \\
93^{\mathrm{a}, \mathrm{A}} \pm 6\end{array}$ & $\begin{array}{l}700^{\mathrm{b}, \mathrm{A}} \pm 141 \\
530^{\mathrm{b}, \mathrm{A}} \pm 104\end{array}$ \\
\hline $\begin{array}{l}\text { TMBS }\left(K O B \mathrm{~mL}^{-1}\right)\left(28^{\circ} \mathrm{C}\right) 10^{5} \\
\text { TMBS }\left(\mathrm{KOB} \mathrm{mL} \mathrm{L}^{-1}\right)(\mathrm{Oda}) 10^{5}\end{array}$ & $\begin{array}{l}8.0^{\mathrm{a}, \mathrm{A}} \pm 1.15 \\
8.0^{\mathrm{a}, \mathrm{A}} \pm 1.15\end{array}$ & $\begin{array}{c}670^{\mathrm{b}, \mathrm{A}} \pm 140 \\
22^{\mathrm{a}, \mathrm{B}} \pm 13\end{array}$ & $\begin{array}{l}40^{\mathrm{a}, \mathrm{A}} \pm 25 \\
87^{\mathrm{a}, \mathrm{B}} \pm 11\end{array}$ & $\begin{array}{l}525^{b, A} \pm 105 \\
530^{b, A} \pm 123\end{array}$ \\
\hline
\end{tabular}

* Satırlarda farklı küçük harfler ile gösterilen fermentasyon süresi arasındaki farklılıklar 0.05 düzeyinde önemlidir.

Sütunlarda farklı büyük harfler ile gösterilen fermentasyon koşulları arasındaki farklılıklar 0.05 düzeyinde önemlidir.

Yapılan bir çalışmada asetik asit bakterileri ve mayaların fermentasyonun 6 . gününde maksimum seviyeye ulaştığı ve fermentasyonun devamında sayıların azaldığı belirtilmektedir. Bu azalmanın düşük $\mathrm{pH}^{\prime}$ ya neden olan asit şokundan kaynaklandığı ifade edilmektedir. Fermentasyon sürecinde mikroorganizma sayısındaki düşüşün aynı zamanda anaerobik ortam ve besin azalmasından kaynaklandığı belirtilmektedir. Azalma nedeni ayrıca alkol fermentasyonu sonucunda oluşan $\mathrm{CO}_{2}{ }^{\prime}$ in selüloz tabaka ile sıvı kısım arasında birikmesinden kaynaklandığı ifade edilmektedir. $\mathrm{CO}_{2}$,
sıVı kısımdan sentetik kısma besin gelişimini engellerken, oksijenin selüloz kısımdan sıvı kısma transferini de kısıtlamaktadır. Bu nedenle kombu çayının sıvı kısımdaki ve selülozik zardaki canlı mikroorganizma konsantrasyonu ile ilgili tartışmalı durumlar ortaya çıktığı belirtilmektedir (Jayabalan ve ark., 2007; Jayabalan ve ark., 2015).

\section{Sonuc}

Günümüzde yoğurt, peynir, kefir, sucuk gibi fermente ürünler probiyotik aktivite göstererek sağlık üzerine 
olumlu etki oluşturmaktadırlar. Kombu çayının diğer geleneksel içecekler gibi popüler olmasının nedeni insan sağlığına yararlı olması ve evde üretiminin kolay olmasından kaynaklanmaktadır. Ülkemizde kombu çayı ile ilgili yapılacak kapsamlı çalışmalar ile kombu çayının daha iyi anlaşılması ve gelecekte tüketiminin arttırılması önem taşımaktadır. Dünya genelinde tüketilen kombu çayı, ülkemizde tam olarak bilinmeyen ve yaygınlaşmayan hafif tatlı ve asidik fermente bir içecektir. Kombu çayının geleneksel olarak üretimi ve fermentasyonun sonlandırılması çayın hoş koku ve tada ulaştığı süre sonunda gerçekleşmektedir. Kombu çayının tadı, fermentasyonun ilk günlerinde hoşa giden ekşi meyve benzeri köpüklü lezzet veya uzun fermentasyon sonucunda sirke tadı şeklinde olmaktadır. Bu süreyi etkileyen faktörlerin birisi de fermentasyon sıcaklığıdır. Dünya çapında farklılık gösteren kombu çayı mantarının mikroorganizma çeşitliliği nedeniyle farklı sıcaklıklarda fermente edilen kombu çayının kompozisyonu farklılık göstermektedir. Mikrobiyal çeşitlilikten dolayı kombu çayının bileşimi her zaman aynı olmamaktadır.

Kombu çayının optimum pH değeri 2.5-4.5 aralığında olmalıdır. Yapılan çalışmada elde edilen değerler bu aralıkta olduğundan fermentasyon için uygulanacak sıcaklık oda veya $28^{\circ} \mathrm{C}$ olması $\mathrm{pH}$ açısından önemsizdir. Fakat $28^{\circ} \mathrm{C}^{\prime}$ de 10 . günde ulaşılacak $\mathrm{pH}$ değerine oda sıcaklığında 15.günde ulaşılmıştır.

Briks değeri fermentasyonun 5.gününde yükselmiş, ilerleyen zamanlarda ise azalma göstermiştir. $\mathrm{Bu}$ da 5.günde kombu çayındaki sakkarozun glikoz ve früktoza parçalandığını göstermektedir.

Kombu çayı üretiminde kombu mantarındaki mayalar alkol oluşturmaktadırlar. Maya sayısı ve ortamın oksijen içeriği oluşan alkolün oranını değiştirmektedir.

Kombu çayının fermentasyon sonucunda üretilmesi ile $L^{*}$ değeri yükselmiş, yani çay renginde açılma olmuştur.

Kombu çayı üretiminde değişik sıcaklık ortamlarında inkübasyon sonucunda oluşan fermente ürünün fenolik bileşik içeriği farklılık göstermiştir. $28^{\circ} \mathrm{C}^{\prime}$ lik fermentasyon sıcaklığında elde edilen kombu çayının fenolik bileşiğinin yükselmesi nedeniyle, kombu çayı üretiminde fenolik bileşikler açısından bu fermentasyon sıcaklığının kullanılması önerilmektedir.

Kombu mantarının farklı bölgelerden getirilmesi ve standart olmayan mikroflora nedeniyle üretim sonucunda farklı bileşenler ortaya çıkmaktadır. Kombu çayının üretiminde 21 günlük inkübasyon süresinin kullanılması ortaya çıkan ürünün asitliği açısından problem oluşturmaktadır. Fermentasyon sıcaklık ve/veya süresinin standartlaştırılması yerine kombu çayı üretimindeki fermentasyon koşullarının tespitinde ürünün $\mathrm{pH}$ değerinin önemli bir kriter olduğu düşünülmektedir. Böylece $28^{\circ} \mathrm{C}^{\prime}$ lik fermentasyon sıcaklığındaki kombu çayı üretimi oda sıcaklığında inkübe edilen kombu çayından daha kısa sürede üretilebildiği sonucuna varılmıştır.

\section{ÖZET}

Amaç: Kombu çayı dünya genelinde tüketilen fakat ülkemizde bilinirliliği az olan, asetik asit fermentasyonu ile alkol fermentasyonunun gerçekleştiği simbiyotik ilişki sonucunda meydana gelen hafif tatlı ve asidik bir içecektir. Sağlık açısından birçok yararı olan bu içeceğin üretim koşullarında sıcaklık önemli bir parametredir. Bu çalışmayla inkübasyon sıcaklığı ve fermentasyon süresinin kombu çayının fizikokimyasal ve mikrobiyolojik özelliklerine etkisinin belirlenmesi amaçlanmıştır.

Yöntem ve Bulgular: Bu çalışmada, Kombu çayı; oda sıcaklığı $\left(15-20^{\circ} \mathrm{C}\right)$ ve $28^{\circ} \mathrm{C}^{\prime}$ deki sıcaklıkta 15 gün fermentasyona tabi tutulmuş ve bu sürede $0 ., 5 ., 10$. ve 15. günlerdeki fizikokimyasal ve mikrobiyolojik özellikler incelenmiştir. Oda sıcaklığında üretilen Kombu çayı örneklerinin $\mathrm{pH}$ değeri 3.51-5.39; briks değerleri 8.719.57; alkol oranı \%1.10-3.07; toplam fenolik madde miktarı 374-364 mg gallik asit $\mathrm{L}^{-1}$; antioksidan aktivitesi \%80.57-76.58 ve yoğunluk değeri 1.037-1.036 $\mathrm{g} \mathrm{mL}^{-1}$ olarak tespit edilmiştir. $28^{\circ} \mathrm{C}^{\prime}$ de fermente edilen Kombu çayı örneklerinin ise $\mathrm{pH}$ değeri 3.22-5.39; briksinin 8.7110.10; alkol içeriğinin \%1.10-3.76; toplam fenolik madde miktarının 374-430 mg gallik asit $\mathrm{L}^{-1}$; antioksidan aktivitesinin \%80.57-80.00 ve yoğunluğunun 1.037$1.035 \mathrm{~g} \mathrm{~mL}^{-1}$ olduğu belirlenmiştir. Her iki sıcaklıkta üretilen Kombu çaylarının $L^{*}, a^{*}$ ve $b^{*}$ değerleri incelendiğinde, farklı fermentasyon koşullarının 5 . ve 10. günlerinde $a^{*}$ ve $b^{*}$ değerleri ile 15 . günün $L^{*}$ ve $a^{*}$ değerlerinde istatistiksel olarak önemli fark $(p<0.05)$ tespit edilmiştir. Farklı sıcaklıklarda üretimi gerçekleştirilen Kombu çayının her iki sıcaklıkta fermentasyon günlerine bağlı olarak mikroorganizma sayılarında önemli düzeyde $(p<0.05)$ artış tespit edilmiştir. Farklı sıcaklıklardaki fermentasyon koşullarına göre maya-küf sayılarındaki artış istatistiksel olarak önemsizken, bakteri sayısı açısından 5 . ve 10 . günlerdeki artış istatistiksel açıdan önemli $(p<0.05$ ) bulunmuştur.

Genel Yorum: Fermentasyon sıcaklık ve/veya süresinin standartlaştırılması yerine kombu çayı üretimindeki fermentasyon koşullarının tespitinde ürünün $\mathrm{pH}$ değerinin önemli bir kriter olduğu düşünülmektedir.

Çalışmanın Önemi ve Etkisi: Bu bulgular ışığında, kombu çayı üretiminde, üretimin standardizasyonunda fermentasyon süresi $28^{\circ} \mathrm{C}^{\prime}$ de 10 gün veya oda 
sıcaklığında 15.gün olması önerilmektedir.

Anahtar Kelimeler: Kombu çayı, Fermentasyon, İnkübasyon sıcaklığı, Fenolik madde, Antioksidan aktivite.

\section{TEŞEKKÜR}

Prof. Dr. Aynur Gül Karahan Çakmakçı'ya makalenin düzenlenmesindeki emeklerinden dolayı teşekkür ederiz.

\section{ÇIKAR ÇATIŞMA BEYANI}

Makale yazarları aralarında herhangi bir çıkar çatışması olmadığını beyan ederler.

\section{ARAŞTIRMACILARIN KATKI ORANI BEYANI}

Yazarlar çalışmaya eşit oranda katkı sağlamış olduklarını beyan eder.

\section{KAYNAKLAR}

Anonymous www.instagram.com/kombucha_mantar "Kenan Arslan". (Erişim tarihi: 02.03.2020)

Amarasinghe H, Weerakkody NS, Waisundara VY (2018) Evaluation of physicochemical properties and antioxidant activities of kombucha "Tea Fungus" during extended periods of fermentation. Food Science and Nutrition 6(3): 659-665.

Belloso-Morales G, Hernandez-Sanchez H (2003) Manufacture of beverage from cheese whey using a tea fungus fermentation. Rev. Latinoam. Microbiol. 45: 5-11.

Blanc PJ (1996) Characterization of the tea fungus metabolites. Biotechnol. Lett. 18: 139-142.

Boulton C, Quain D (2001) Brewing Yeast and Fermentation. Blackwell Science Ltd. ISBN 0-63205475-1

Chakravorty S, Bhattacharya S, Chatzinotas A, Chakraborty W, Bhattacharya D, Gachhui R (2016) Kombucha tea fermentation: Microbial and biochemical dynamics. Int. J. Food Microbiol. 220: 63-72.

Chen C, Liu BY (2000) Changes in major components of tea fungus metabolites during prolonged fermentation. J. Appl. Microbiol. 89: 834-839.

Chu SC, Chen C (2006) Effects of origins and fermentation time on the antioxidant activities of Kombucha. Food Chem. 98: 502-507.
Coton M, Pawtowski A, Taminiau B, Burgaud G, Deniel F, Coulloumme-Labarthe L, Fall A, Daube G, Coton E (2017) Unraveling microbial ecology of industrialscale Kombucha fermentations by metabarcoding and culture-based methods. FEMS Microbiol. Ecology 93(5): fix048.

Çakmakçı AGK, Arıdoğan BC, Çakmakçı ML (2017) Genel Mikrobiyoloji Uygulama Kılavuzu. Süleyman Demirel Üniversitesi, Mühendislik Fakültesi, SDÜ Yayınları, Yayın No:24. Isparta.

El-Siddig Ahmed S (2003) Biochemical and Microbial Changes During Fermantation of Tea Fungus (Kombucha). University of Khartoum, Faculty of Agriculture, Department of Botany and Agricultural Biotechnology.

Erkmen O (1996) A Laboratory Manuel In general Microbiology. University of Gaziantep. Department of Food Engineering. Published by the University of Gaziantep. ISBN 975-7375-11-X.

Gramza-Michałowska A, Kulczyński B, Xindi Y, Gumienna M (2016) Research on the effect of culture time on the kombucha tea beverage's antiradical capacity and sensory value. Acta Sci. Pol. Technol. Aliment. 15(4): 447-457.

Güldane M, Bayram M, Topuz S, Kaya C, Gök HB, Bülbül M, Koç M (2017) Beyaz, siyah ve yeşil çay kullanılarak üretilen Kombuchaların bazı özelliklerinin belirlenmesi. Gaziosmanpaşa Üni. Zir. Fak. Derg. 34(1): 46-56.

Illeri-Büyükoğlu T, Taşçı F, Şahindokuyucu F (2010) Kombucha ve Sağlık üzerine Etkileri. Uludağ Üniv. J. Fac. Vet. Med. 29(1): 69-76.

Jayabalan R, Marimuthu S, Swaminathan K (2007) Changes in content of organic acids and tea polyphenols during kombucha tea fermentation. Food Chem. 102: 392-398.

Jayabalan $R$, Subathradevi $P$, Marimuthu $S$, Sathishkumar M, Swaminathan K (2008) Changes in free-radical scavenging ability of Kombucha tea during fermentation. Food Chem. 109: 227-234.

Jayabalan R, Malbasa RV, Loncar ES, Vitas JS, Sathishkumar M (2014) A Review on KombuchaTeaMicrobiology Composition, Fermentation, Beneficial Effects, Toxicity, and Tea Fungus. Compr. Rev. Food Sci. Food Saf. 13: 538-550.

Jayabalan R, Malbasa RV, Sathishkumar M (2015) Kombucha Tea: Metabolites, In: Fungal Metabolites (Eds. Mérillon JM, Ramawat KG), Springer, Cham. $\mathrm{P}$ 400. https://doi.org/10.1007/978-3-319-19456-1 
Karahan AG, Akoğlu A, Çakır i, Kart A, Çakmakçı ML, Uygun A, Göktepe F (2011) Some properties of bacterial cellulose produced by new native strain Gluconacetobacter sp. A06O2 obtained from Turkish vinegar. J. Appl. Polymer Sci. 121: 1823-1831.

Kallel L, Desseaux V, Hamdi M, Stocker P, Ajandouz E (2012) Insights into the fermentation biochemistry of kombucha teas and potential impacts of kombucha drinking on starch digestion. Food Res. Int. 49: 226-232.

Kurtzman CP, Robnett CJ, Basehoar-Powers E (2001) Zygosaccharomyces kombuchaensis, a new ascosporogenous yeast from Kombucha tea. Yeast Res. 1: 133-138.

Liu CH, Hsu WH, Lee FL, Liao CC (1996) The isolation and identification of microbes from a fermented tea beverage, Haipao, and their interactions during Haipao fermentation. Food Microbiol. 13: 407-415.

Loncar E, Djuric M, Malbasa R, Kolarov L, Klasnja M (2006) Influence of working conditions upon Kombucha conducted fermentation of black tea. Food Bioprod. Process 84: 186-192.

Malbasa RV, Loncar ES, Vitas JS, Canadanovic-Brunet JM (2011) Influence of starter cultures on the antioxidant activity of kombucha beverage. Food Chem. 127(4): 1727-1731.

Malbasa RV, Milanovic SD, Loncar ES, Djuric MS, Caric MD, llicic MD, Kolarov L (2009) Milk-based beverages obtained by Kombucha application. Food Chem. 112: 178-184.

Malbasa R, Loncar E, Drujic M (2008a) Comparison of products of Kombucha fermentation on sucrose and molasses. Food Chem. 106: 1039-1045.

Malbasa R, Loncar E, Djuric M, Dosenovic I (2008b) Effect of sucrose concentration on the products of Kombucha fermentation on molasses. Food Chem. 108: 926-932.

Malbasa RV, Loncar ES, Djuric MS, Kolarov LA, Klasnja MT (2005) Batch fermentation of black tea by kombucha: A contribution to scale-up. APTEFF 36: 1266.

Malbasa RV, Maksimovic MZ, Loncar ES, Brankovic TI (2004) The influence of starter cultures on the content of vitamin B2 in tea fungus beverages. CEJOEM 10(1): 79-83.

Malczewski AA (2001) Kombucha. Çev. Şebnem Tirkeş, İm Yayın Tasarım, Hünkar Ofset, Mecidiyeköy, İstanbul
Neffe-Skocinska K, Sionek B, Ścibisz I, KolożynKrajewska D (2017) Acid contents and the effect of fermentation condition of Kombucha tea beverages on physicochemical, microbiological and sensory properties. CyTA - Journal of Food 15(4): 601-607.

Nguyen VT, Flanagan B, Gidley MJ, Dykes GA (2008) Characterization of cellulose production by a Gluconacetobacter xylinus strain from Kombucha. Curr. Microbiol. 57: 449-453.

Primiani N, Pujiati MM, Ardhi IS (2018) Kombucha fermentation test used for various types of herbal Teas. Journal of Physics: Conference Series 1025, 012073, pp 9.

Pure AE, Pure M (2016a) Antioxidant, Antibacterial and Color Analysis of Garlic Fermented in Kombucha and Red Grape Vinegar. Appl. Food Biotech. 3(4): 246252.

Pure AE, Pure ME (2016b) Antioxidant and antibacterial activity of kombucha beverages prepared using banana peel, common nettles and black tea infusions. Appl. Food Biotech. 3(2): 125-130.

Reiss J (1994) Influence of different sugars on the metabolism of the tea fungus. Z. Lebensm Unters Forsch 198: 258-261.

Sievers M, Lanini C, Weber A, Schuler-Schmid U, Teuber $M$ (1995) Microbiology and Fermentation Balance in a Kombucha Beverage Obtained from a Tea Fungus Fermentation. System. Appl. Microbiol. 18: 590-594

Singh RP, Murthy KNC, Jayaprakasha GK (2002) Studies On The Antioxidant Activity Of Pomegranate (Punica Granatum) Peel And Seed Extracts Using In Vitro Models. J. Agric. Food Chem. 50: 81-86.

Sreeramulu G, Zhu Y, Knol W (2000) Kombucha fermentation and its antimicrobial activity. J. Agric. Food Chem. 48: 2589-2594.

Sreeramulu G, Zhu Y, Knol W (2001) Characterization of antimicrobial activity in Kombucha fermentation. Acta Biotechnol. 21: 49-56.

Sun TZ, Li JS, Chen C (2015) Effects of blending wheatgrass juice on enhancing phenolic compounds and antioxidant activities of traditional kombucha beverage. J. Food and Drug Analysis 23(4): 709-718.

Şafak S, Mercan N, Aslım B, Beyatlı Y (2002) A study on the production of poly-betahydroxybutyrate bye some eukaryotic microorganisms. Turk Electron. J. Biotechnol. Special Issue, 11-17.

Şafak S, Yüksekdağ ZN, Aslım B, Beyatlı Y (2003) Komboçya çayından izole edilen mayaların antimikrobiyal aktivitelerinin incelenmesi. Gıda 28 (1): 105-108. 
Teoh AL, Heard G, Cox J (2004) Yeast ecology of Kombucha fermentation. Int. J. Food Microbiol. 95: 119-126.

Uçan Türkmen F, Mercimek Takçı HA, Sağlam H, Şekeroğlu N (2019a) Investigation of Some Quality Parameters of Pomegranate, Sumac and Unripe Grape Sour Products from Kilis Markets. Qual. Assur. Saf. Crop. Foods 11(1): 61-71.

Uçan Türkmen F, Mercimek Takçı HA, Sarıgüllü Önalan $\mathrm{FE}$, Sağlam H (2019b) Arum dioscoridis Ekstraktlarının Toplam Fenolik, Flavonoid İçerikleri ile Antioksidan ve Antibakteriyel Aktivitelerinin Araştırılması. HRU Muh. Derg. 4(1): 102-108.

Wang $\mathrm{Y}$, Ji B, Wu W, Wang R, Yang Z, Zhang D, Tian W (2014). Hepatoprotective effects of Kombucha tea: identification of functional strains and quantification of functional components. J. Sci. Food Agric. 94: 265272.
Velicanski AS, Cvetkovic DD, Markov SL, Tumbas Saponjac VT, Vulic JJ (2014) Antioxidant and Antibacterial Activity of the Beverage Obtained by Fermentation of Sweetened Lemon Balm (Melissa officinalis L.) Tea with Symbiotic Consortium of Bacteria and Yeasts. Food Technol. Biotechnol. 52(4) 420-429.

Velicanski AS, Cvetkovic DD, Markov SL, Tumbas VT, Savatovic SM (2007) Antimicrobial and antioxidant activity of lemon balm Kombucha. APTEFF 38: 165172. 